George A. Arndt MD, John Topp DO, Jane Hannah CRNA, Thomas S. McDowell MD PhD, Anita Lesko CRNA

\section{Intubation via the LMA using a Cook retrograde intubation kit}

Purpose: We report two cases of difficult intubation where a laryngeal mask airway (LMA) was used and changed to a conventional endotracheal tube using a retrograde intubation set.

Clinical findings: In two patients, following induction of anaesthesia, the trachea could not be intubated in the conventional fashion with a blade. In both patients an LMA was inserted to achieve an airway. In both patients intubation with a conventional endotracheal tube was required. A Cook Retrograde Intubation Kit and fibreoptic bronchoscope were used to change the LMA to conventional endotracheal tube without problems.

Conclusion: The Cook retrograde intubation allows an LMA to be replaced with an endotracheal tube with an ID greater than $6 \mathrm{~mm}$ with a \#3 or $7 \mathrm{~mm}$ with a \#5 LMA. This technique places an exchange stylet into the airway which is superior to a conventional guidewire. This method allows the ainway to be maintained until the LMA is exchanged with an endotracheal tube. Anaesthesia may be maintained and the airway instrumented without difficulty using this technique.

Objectif : Rapporter deux cas d'intubation difficile où un masque laryngé (ML) a d'abord été utilisé pour ensuite être remplacé par un tube endotrachéal conventionnel en utilisant une trousse d'intubation rétrograde.

Observations cliniques : Chez deux patients, suite à l'induction de l'anesthésie, l'intubation conventionnelle avec un laryngoscope s'est avérée impossible. Chez les deux patients, l'insertion d'un ML a permis d'obtenir une voie aérienne, mais une intubation conventionnelle était requise. Une trousse d'intubation rétrograde Cook et un fibroscope ont été utilisés pour remplacer sans difficulté le ML par un tube endotrachéal.

Conclusion : La trousse d'intubation rétrograde Cook permet de remplacer un ML par un tube endotrachéal de diamètre interne plus grand que $6 \mathrm{~mm}$ pour le $\mathrm{ML} \# 3$ et plus grand que $7 \mathrm{~mm}$ pour le \#5. Cette technique permet de placer dans les voies respiratoires un stylet d'échange supérieur à la broche guide conventionnelle. Cette méthode permet de maintenir les voies aériennes ouvertes jusqu'à ce que le ML puisse être remplacé par un tube endotrachéal; elle permet de poursuivre l'anesthésie et d'instrumenter sans difficulté les voies respiratoires.

From the Department of Anesthesiology, University of Wisconsin Medical School, Madison, Wisconsin.

Address correspondence to: George A. Arndt MD, Department of Anesthesiology, University of Wisconsin Medical School, B6/319 CSC, 600

Highland Avenue, Madison, WI 53792-3272 USA. Phone: 608-263-8100; Fax: 608-263-0575; E-Mail: gaarndt@facstaff.wisc.edu Accepted for publication December 18, 1997. 
M ANAGEMENT of the unanticipated difficult airway presents a clinical dilemma to the anaesthetist when it is encountered. The laryngeal mask airway (LMA) is an accepted step in the management of a difficult airway and part of the ASA algorithm for difficult airway management. Placement of the LMA in patients whose tracheas are difficult to intubate is an acceptable way of establishing an airway for ventilation and oxygenation. ${ }^{1}$ Once the LMA is in place and an airway is achieved a new set of priorities may be addressed as to which is the most acceptable means of achieving a definitive airway.

The fibreoptic bronchoscope may be used to place an endotracheal tube or guide wire into the trachea using the LMA as a conduit. ${ }^{2}$ We report a modification of this guidewire technique using the Cook Retrograde Intubation Set and a paediatric fibreoptic bronchoscope in two cases of unanticipated difficult intubation. We believe this technique offers advantages over other methods. Using this technique, we were able to intubate the trachea quickly while maintaining a patent airway during bronchoscopy and placement of a guidewire and exchange stylet.

\section{Case report}

Case \#1

A 26-yr-old woman with end-stage renal failure secondary to familial glomerular nephritis was scheduled for bilateral laparoscopic nephrectomy. (Her past medical history was remarkable for end-stage renal failure secondary to familial glomerular nephritis treated successfully with a kidney transplant.) She had undergone renal transplantation two years previously and the trachea had been easily intubated with a $7.5 \mathrm{~mm}$ endotracheal tube using a MAC \#3 blade. The patient weighed $80 \mathrm{~kg}$ and the airway examination was unremarkable. Her preoperative medication included $50 \mathrm{mg}$ b.i.d. cyclosporine and $10 \mathrm{mg}$ q.d. prednisone.

On the morning of surgery, the patient was taken to the operating room, an 18-gauge iv cannula was inserted into her left hand, and an infusion of lactated Ringers begun. Routine monitors were placed and anaesthesia was induced with $100 \mu \mathrm{g}$ fentanyl and $250 \mathrm{mg}$ thiopentone. A bag and mask airway was easily achieved and the lungs were ventilated with oxygen $100 \%$ and isoflurane $0.8 \%$ end-tidal, and $12 \mathrm{mg}$ cisatracurium was given. Direct laryngoscopy was then performed using a MAC \#3 blade. Visualisation of the glottic aperture was impossible and a large amount of tonsillar tissue was noted at the base of the tongue. The blade was then removed. A bag and mask airway was reestablished and laryngoscopy was again attempted using a MAC \#4 blade. Again it was impossible to visualise the glottic aperture and only tonsillar tissue was visualised.

The patient was placed in the sniffing position, cricoid pressure was applied, and a third direct laryngoscopy was attempted with a Miller \#2 blade. It was again impossible to view the glottis aperture. Neither the vocal cords nor the epiglottis could be visualised, only tonsillar tissue. A bag and mask airway was then reestablished. The lungs were ventilated with oxygen $100 \%$ and isoflurane $0.8 \%$ end-tidal. A laryngeal mask airway, Cook Retrograde Intubation Set, and a Pentax $3.4 \mathrm{~mm}$ OD paediatric bronchoscope were brought into the room. A \#3 LMA was inserted into the patient's airway and the cuff inflated. An airway was established and the lungs were ventilated without difficulty. A standard bronchoscopic adapter was placed between the LMA connector and the anaesthesia circuit. The paediatric bronchoscope was then advanced through the bronchoscopic adapter down the tubular portion of the LMA while ventilating the lungs using the bag of the anaesthesia machine maintaining anaesthesia with isoflurane in $100 \%$ oxygen. The fibreoptic bronchoscope was then advanced through the laryngeal mask airway and the glottic aperture was identified allowing easy passage of the fibreoptic bronchoscope through the glottic aperture into the patient's trachea and the carina identified. During this time the lungs were ventilated without any problems.

The noncurved end of the retrograde wire of a Cook Retrograde Intubation Set was advanced through the working channel of the fibreoptic bronchoscope and, under direct visualisation, was noted to exit the end of the bronchoscope in the trachea. The bronchoscope was removed leaving the retrograde wire in the trachea and exiting through the bronchoscope port. This wire is $110 \mathrm{~cm}$ long allowing removal of the fibreoptic bronchoscope while leaving the retrograde wire in place.

The Cook Retrograde Intubation Set contains a \#11 Fr., $70 \mathrm{~cm}$ long stiffening stylet, tapered at both ends, designed to be advanced over the wire. The stiffening stylet was then advanced over the wire to lie in the patient's trachea. The patient now had an airway using the laryngeal mask airway and a retrograde stylet in place through the LMA into the trachea. During the bronchoscopy, placement of the wire and placement of the stylet, we were able to ventilate the lungs adequately using the anaesthesia machine and the LMA with a bronchoscopic adapter. The trachea was then intubated by removing the laryngeal mask airway over the retrograde stylet and placing an endotracheal tube over the stylet into the patient's airway. A $7.0 \mathrm{~mm}$ cuffed endotracheal tube was placed without difficulty. The endo- 
tracheal tube had a bronchoscopic adapter attached before intubation to allow the retrograde stylet to be placed through the endotracheal tube and achieve ventilation with the anaesthesia machine before stylet removal. When breath sounds and $\mathrm{CO}_{2}$ were noted to be present, the stiffening stylet and guidewire were removed. Bilateral laparoscopic nephrectomy was performed without incident and, at the end of the case, the trachea was extubated following reversal of neuromuscular relaxation and the patient was taken to the recovery room. Later ENT examination showed that she had prominent lingual tonsils and tonsillary tissue. Her remaining course was unremarkable.

\section{Case \#2}

A 53-yr-old man presented for left uteroscopic stone extraction under general anaesthesia. The patient weighed $157 \mathrm{~kg}$ and had undergone general anaesthesia three times previously for knee surgery and stone removal. The patient reported no history of airway difficulty. Airway examination was unremarkable except for obesity with a larger than normal tongue and a Mallampati class two classification. Preoperative medication included Lotensin and there was a history of hypertension. Prior to entering the operating room, an 18-gauge intravenous catheter was placed, infusion of lactated Ringers begun and $2 \mathrm{mg}$ midazolam administered $i v$. In the operating room, routine monitors were placed. General anaesthesia was induced with $500 \mathrm{mg}$ thiopentone and a bag and mask airway established with oxygen $100 \%$ before administering $140 \mathrm{mg}$ succinylcholine. Direct laryngoscopy was performed twice with a MAC \#4 blade using cricoid pressure and the sniffing position. No airway structures could be visualised due to the presence of a large amount of soft tissue. A \#5 LMA was placed and an airway established. The lungs were ventilated without problem and anaesthesia was maintained with oxygen and desflurane $9 \%$ end-tidal. A paediatric bronchoscope and Cook Retrograde Intubation Set were obtained and a bronchoscopic port attached to the LMA. Bronchoscopy was performed and the trachea entered. Examination showed a large amount of soft tissue at the glottic aperture. The retrograde set was used, as previously, and the trachea intubated with a $7.0 \mathrm{~mm}$ endotracheal tube. The stone extraction proceeded without difficulty and the trachea was extubated at the end of the procedure without difficulty. The postoperative course was unremarkable.

\section{Discussion}

The LMA is an accepted means of managing the difficult airway. It is indicated for establishing an airway in patients whose tracheas are difficult to intubate or in patients whose lungs cannot be ventilated or oxygenated before progressing to cricothyroidotomy. ${ }^{3}$ Once the laryngeal mask airway is in place, the clinician is faced with a dilemma: 1) Canceling the case, 2) Waking the patient and attempting awake fibreoptic intubation, 3) Proceeding with the case using the laryngeal mask airway as a definitive airway, or 4) Placing an alternative airway such as an endotracheal tube. A $6.0 \mathrm{~mm}$ endotracheal tube may be placed through the \#4 LMA either blindly or using a fibreoptic bronchoscope. A guidewire technique may be used to change the LMA to a larger endotracheal tube. Fibreoptic bronchoscopy makes either technique less difficult than placing the endotracheal tube or guidewire blindly. The laryngeal mask airway limits the size of endotracheal which may be placed through it.

The use of a guidewire has been described ${ }^{4}$ with the fibreoptic bronchoscope as a means of changing the LMA to an endotracheal tube. A major pitfall in this technique is that the guidewire can telescope during advancement of the endotracheal tube causing the tube to go into the oesophagus. In one study using a Cook airway exchange catheter, the success rate of correct endotracheal tube placement despite good LMA position was only $30 \% .{ }^{5}$ An alternative guidewire rechnique is possible using a Cook Retrograde Intubation Set. This retrograde set contains a $110 \mathrm{~cm}$ long, $0.97 \mathrm{~mm}$ diameter guidewire and a $70 \mathrm{~cm}, \# 11 \mathrm{Fr}$. diameter stylet indexed to the guidewire. The guidewire easily passes through the working port of a paediatric bronchoscope. With this technique and an LMA modified with a bronchoscopic port, it is possible to place the guidewire under direct vision, examine the wire after placement, place a stiffening stylet and ventilate the lungs. The LMA is then removed leaving the stylet in place and intubating the lungs over the stylet. The only time a definitive airway is not available is during the changing of the endotracheal tube. The paediatric bronchoscope with its small OD also allows easy ventilation as it takes only a small portion of the cross sectional area available in the LMA. In addition, this method will allow any size endotracheal tube from 4.0 to $8.0 \mathrm{~mm}$ ID.

\section{Conclusion}

We report a technique that can facilitate intubation and provide an alternative to currently used methods of airway management. Ventilation can be maintained throughout airway manipulation providing delivery of oxygen and anaesthetic gases. This technique allows definitive airway management in the case of lingual tonsils where cerebral anoxia and death has been reported. ${ }^{6}$ It also allows airway management and intubation in patients with unanticipated excessive soft 
tissue in the airway making conventional intubation and laryngoscopy impossible.

The LMA provides a conduit to relieve the soft tissue obstruction, to maintain oxygenation, ventilation and delivery of anaesthetic gases and allow instrumentation of the airway. The Cook Retrograde Intubation Set allows an improved method of the guidewire technique to exchange an LMA for an endotracheal tube.

\section{References}

1 Heath $M L$. Endotracheal intubation through the laryngeal mask - helpful when laryngoscopy is difficult or dangerous. Eur J Anaesthesiol 1991; 4: 41-5.

2 Silk JM, Hill HM, Calder I. Difficult intubation and the laryngeal mask. Eur J Anaesthesiol 1991; 4: 47-51.

3 Benumof $\Omega$. Laryngeal mask airway and the ASA difficult airway algorithm. Anesthesiology 1996; 84: 686-94.

4 Hasan $M A$, Black $A E$. A new technique for fibreoptic intubation in children. Anaesthesia 1994; 49: 1031-3.

5 Brimacombe J, Berry A. Placement of a Cook airway exchange catheter via the laryngeal mask airway (Letter). Anaesthesia 1993; 96: 351-2.

6 Jones $D H$, Cohle $S D$. Unanticipated difficult airway secondary to lingual tonsillar hyperplasia. Anesth Analg 1993; 77: 1285-8. 